\title{
Penerapan Media Pembelajaran Audio-Visual tentang Peningkatan Sesamol sebagai Zat Penghambat Pertumbuhan Sel Kanker menggunakan Teknik Motion Graphic
}

\author{
Nury Nurfajry, Herlambang Saputra, Ema Laila \\ Program Studi Teknologi Informatika Multimedia Digital, \\ Politeknik Negeri Sriwijaya \\ Jalan Srijaya Negara, Palembang 30139, Indonesia \\ nury.fajry@gmail.com, herlambang@polsri.ac.id,emmalaksemana@gmail.com
}

Diterima: 12 September 2019. Disetujui: 19 September 2019. Dipublikasikan : November 2019

\begin{abstract}
Abstrak - Perkembangan teknologi multimedia dewasa ini telah membawa banyak kemajuan, salah satunya dalam bidang informasi. Penyampaian informasi tidak melulu berupa tulisan, namun sudah mencapai format audio visual, contohnya adalah media pembelajaran audio-visual. Proses pembelajaran dengan menggunakan media audio-visual dapat memperlancar pemahaman dan memperkuat ingatan. Hasil belajar mahasiswa yang diajar dengan menggunakan media audio-visual memiliki skor jauh lebih tinggi dibanding dengan mahasiswa yang diajar menggunakan pendekatan konvensional. Dengan keunggulan yang dimiliki media pembelajaran audio-visual, penulis membuat sebuah media pembelajaran tentang peningkatan sesamol sebagai zat penghambat pertumbuhan sel kanker menggunakan teknik motion graphic guna membantu para pelaku pendidikan dalam mengajar dan menciptakan suasana belajar yang lebih menarik.
\end{abstract}

Kata Kunci : audio-visual; motion graphic; wijen

\section{PENDAHULUAN}

Berbagai macam minyak nabati sudah tersebar di pasaran seperti minyak kelapa sawit, minyak jagung, minyak zaitun dan minyak wijen. Wijen telah lama dikenal sebagai penghasil minyak nabati (minyak wijen) yang memiliki banyak khasiat terhadap kesehatan manusia. Wijen di Indonesia biasanya dijadikan sebagai pelengkap makanan kudapan dan snack, namun beberapa diantaranya juga ada yang sudah memproduksi minyak wijen meskipun masih dalam skala kecil [1].
Kanker merupakan suatu kondisi dimana sel telah kehilangan pengendalian dan mekanisme normalnya, sehingga mengalami pertumbuhan yang tidak normal, cepat dan tidak terkendali [2]. Ada beberapa macam jenis kanker yang telah teridentifikasi, salah satunya adalah kanker payudara Kanker payudara merupakan suatu penyakit neoplasma yang ganas yang berasal dari parenchyma [3]. Kanker payudara ini merupakan masalah yang dapat menimbulkan kesengsaraan dan kematian pada manusia. Selain dengan menjalani pengobatan medis, pertumbuhan sel kanker ternyata dapat ditekan dengan zat-zat yang terkandung didalam berbagai bahan makanan, salah satunya adalah dengan senyawa sesamol yang terdapat di dalam wijen.

Sesamol sebagai senyawa pada biji wijen dapat menghambat pertumbuhan sel kanker (growth arrest) dan menginduksi apoptosis sel kanker payudara [4]. Selain itu, penelitian Aldila Din Pangawikan pada tahun 2016 mengemukakan bahwa kandungan sesamol dalam wijen bisa ditingkatkan dengan menggunakan heat treatment. Hal ini tentunya merupakan kabar baik yang harus disampaikan kepada kepada mahasiswa yang sedang menempuh pendidikan di bidang pangan agar pemanfaatan wijen tidak sebatas bahan pelengkap makanan tetapi lebih dari itu. Informasi ini bisa saja disampaikan kepada mahasiswa melalui proses pembelajaran konvensional, akan tetapi dengan metode pembelajaran seperti ini cenderung berorientasi pada target penguasaan materi dan proses pembelajaran konvensional membutuhkan waktu yang relatif lama.

Berbeda dengan pembelajaran konvensional, proses pembelajaran dengan menggunakan media audio-visual dapat memperlancar pemahaman dan memperkuat ingatan karena informasi yang 
disampaikan dengan menggabungkan semua elemen multimedia ini membuat informasi dapat diterima oleh indera pendengaran, visual dan lebih dekat dengan bentuk aslinya di dunia nyata [5]. Dengan kata lain, pembelajaran dengan menggunakan media seperti audio-visual dapat membuat proses pembelajaran menjadi lebih efektif [6].

Hasil belajar mahasiswa yang diajar dengan menggunakan media audio-visual pun memiliki skor jauh lebih tinggi dibanding dengan mahasiswa yang diajar menggunakan pendekatan konvensional. Skor akhir yang dimiliki kelompok eksperimen audiovisual sebesar 86,00 sedangkan kelompok eksperimen konvensional hanya memperoleh skor sebesar 78,33 [7]. Media pembelajaran audio-visual terdiri dari berbagai macam bentuk, beberapa diantaranya yaitu berbentuk video, slide-show (powerpoint), motion graphic atau bahkan animasi 3 dimensi yang memiliki kelebihan dan kekurangan masing-masing. Sebagai contoh media pembelajaran audio-visual dengan media slide-show (powerpoint) memiliki gerakan yang terkesan kaku dan aset animasi terbatas karena tools yang tersedia di powerpoint juga terbatas [8]. Selain itu, media pembelajaran audio-visual dengan media slide-show juga hanya bisa dibuka dengan aplikasi tertentu. Berbeda dengan slide-show, media pembelajaran audio-visual yang berbentuk video motion graphic memiliki gerakan yang lebih leluasa, dapat mengkreasikan aset animasi dan hasil yang dapat dibuka dengan mudah dan fleksibel dengan menggunakan video player di handphone, laptop ataupun YouTube.

Berdasarkan uraian di atas, penulis bermaksud membuat sebuah media pembelajaran audio-visual berbentuk motion graphic dengan memanfaatkan perangkat lunak pembuatan animasi dan pengeditan video tentang senyawa sesamol yang terkandung dalam minyak wijen sebagai zat untuk menghambat pertumbuhan kanker. Hasil dari pembuatan media pembelajaran audio-visual ini akan didistribusikan kepada mahasiswa semester VI Jurusan Teknologi Hasil Pertanian Universitas Sriwijaya melalui kanal YouTube agar menjadi bahan pendukung dalam proses pembelajaran.

\section{TINJAUAN PUSTAKA}

\section{A. Motion Graphic}

Motion graphic sebenarnya merupakan bagian dari teknik animasi, dimana motion graphic adalah salah satu kategori bidang animasi yang dioperasikan menggunakan perekaman video atau teknologi animasi untuk meciptakan ilusi gerak atau rotasi dan biasanya dikombinasikan dengan audio untuk digunakan dalam proyek multimedia untuk berbagai keperluan publikasi [9].
Pembuatan media pembelajaran audio-visual dengan teknik motion graphic ini menggunakan perangkat keras diantaranya laptop, mouse, earphone dan didukung dengam perangkat lunak desain grafis, pembuatan animasi, pengeditan video dan pengeditan suara.

\section{B. Alur Pembuatan Media Pembelajaran}

Proses pembuatan media pembelajaran audiovisual ini dimulai dengan konsep, perancangan, pembuatan hingga analisis hasil pengujian. Perancangan dalam penelitian ini yaitu berupa perancangan media pembelajaran audio-visual dan perancangan kuesioner. Dari perancangan media pembelajaran audio-visual dan perancangan kuesioner tersebut, dapat diketahui solusi dari permasalahan yang ada sebelumnya. Perancangan media pembelajaran audio-visual ini menggunakan metode pengembangan multimedia Luther. Proses perancangan media pembelajaran audio-visual ini dijelaskan pada Gambar1.

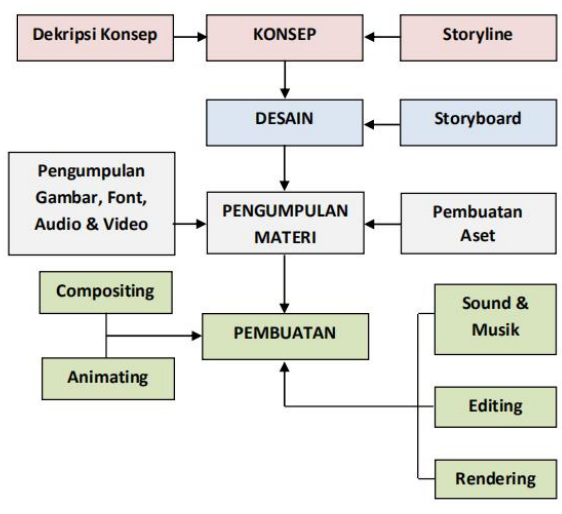

Gambar 1 Alur Pembuatan Media Pembelajaran

Menurut Luther, pengembangan multimedia dapat dilakukan dengan metode MDLC (Multimedia Development Life Cycle) [10], yaitu:

- Konsep (Concept)

Tahap konsep merupakan proses untuk menentukan konsep-konsep yang digunakan dalam membuat media pembelajaran audiovisual, tujuan dan siapa pengguna program (identifikasi audiens).

- Desain (Design)

Tahap dimana pembuat dan pengembang proyek multimedia menjabarkan secara rinci apa yang akan dilakukan dan bagaimana proyek multimedia tersebut akan dibuat.

- Pengumpulan Materi (Material Collecting) Material collecting merupakan proses pengumpulan segala sesuatu yang dibutuhkan dalam pembuatan proyek.

- Pembuatan (Assembly)

Proses pembuatan proyek media pembelajaran audio-visual. Materi dan Aset-aset multimedia 
yang sudah dikumpulkan kemudian dirangkai dan disusun sesuai storyboard dan storyline.

Semua tahap dilakukan secara berurutan dan sesuai dengan schedule yang telah ditentukan agar tidak ada proses yang terlewatkan yang akan berdampak buruk pada manajemen produksi dan berakibat terjadinya penambahan jadwal produksi.

\section{1) Deskripsi Konsep}

Tabel I merupakan deskripsi konsep dari media pembelajaran audio-visual yang akan dibuat.

\begin{tabular}{|c|l|}
\multicolumn{2}{l}{ TABEL I. DESKRIPSI KONSEP } \\
\hline Deskipsi & \multicolumn{1}{c|}{ Keterangan } \\
\hline Judul & $\begin{array}{l}\text { Senyawa Sesamol dalam Minyak Wijen } \\
\text { sebagai Zat untuk Menghambat Pertumbuhan } \\
\text { Kanker }\end{array}$ \\
\hline Jenis & $\begin{array}{l}\text { Media Pembelajaran Audio-Visual (Motion } \\
\text { Graphic) }\end{array}$ \\
\hline $\begin{array}{c}\text { Target } \\
\text { Audiens }\end{array}$ & $\begin{array}{l}\text { Mahasiswa semester VI Fakultas Teknologi } \\
\text { Pertanian, Jurusan Teknologi Pertanian Hasil } \\
\text { Pertanian, Universitas Sriwijaya pada Mata } \\
\text { Kuliah Antioksidan. }\end{array}$ \\
\hline $\begin{array}{c}\text { Estimasi } \\
\text { Durasi }\end{array}$ & $6-10$ menit \\
\hline
\end{tabular}

Media pembelajaran audio-visual ini menjelaskan tentang peningkatan sesamol dalam biji wijen yang dipanaskan dimulai dengan menjelaskan macam-macam wijen serta manfaatnya, kemudian proses terjadinya peningkatan sesamol dengan pemanasan hingga khasiat sesamol yang dapat menekan pertumbuhan sel kanker payudara (MCF-7). Data dalam media pembelajaran audio-visual ini merupakan data yang dapat dipertanggung jawabkan kebenarannya.

Setelah menentukan konsep, tahap selanjutnya yaitu menyusun syoryline. Storyline adalah inti dari sebuah naskah yang di ambil dari gagasan utama yang dibuat seperti alur cerita [11]. Tabel II merupakan beberapa bagian dari storyline media pembelajaran ini.

TABEL II.STORYLINE

\begin{tabular}{|c|c|c|}
\hline Scene & Video & Narasi \\
\hline 1 & $\begin{array}{l}\text { Macam macam } \\
\text { minyak nabati dan } \\
\text { manfaat minyak wijen }\end{array}$ & $\begin{array}{l}\text { Berbagai macam minyak } \\
\text { nabati seperti minyak } \\
\text { kelapa sawit, minyak } \\
\text { jagung, minyak zaitun } \\
\text { dan minyak wijen telah } \\
\text { banyak diperjualbelikan. } \\
\text { Masyarakat dunia pun } \\
\text { sudah mengetahui } \\
\text { berbagai manfaat dari } \\
\text { minyak nabati, seperti } \\
\text { minyak wijen yang baik } \\
\text { untuk kesehatan jantung, } \\
\text { penambah rasa makanan, } \\
\text { antibakteri untuk kulit } \\
\text { dan masih banyak lagi. }\end{array}$ \\
\hline 2 & $\begin{array}{l}\text { Pemanfaatan } \\
\text { Indonesia } \\
\text { a. Pelengkap } \\
\quad \text { makanan } \\
\text { b. Minyak: }\end{array}$ & $\begin{array}{l}\text { Di Indonesia, Balai } \\
\text { Penelitian } \\
\text { pemanis dan sanaman } \\
\text { (Balittas) mengeluarkan } \\
\text { beberapa varietas biji }\end{array}$ \\
\hline
\end{tabular}

\begin{tabular}{|c|c|c|}
\hline & $\begin{array}{ll}- & \text { Langsung } \\
& \text { Press } \\
\text { - } & \text { Dipanaskan } \\
& \text { dulu }\end{array}$ & 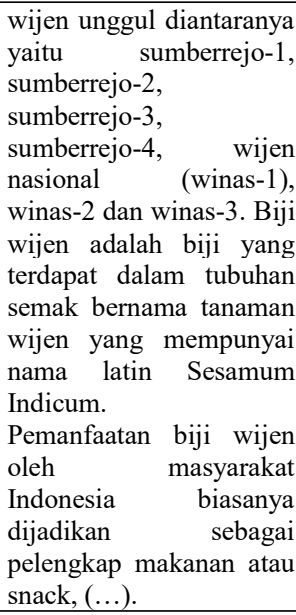 \\
\hline 3 & $\begin{array}{l}\text { Sesamol lebih sedikit } \\
\text { dibandingkan senyawa } \\
\text { lainnya }\end{array}$ & $\begin{array}{lr}\text { Lantas, mengapa } \\
\text { senyawa sesamol bisa } \\
\text { meningkat? Jadi, selain } \\
\text { sesamol, biji wijen juga } \\
\text { mengandung senyawa } \\
\text { lignan yang lain yaitu } \\
\text { sesamin Dan sesamolin. } \\
\text { Yang berperan penting } \\
\text { dalam meningkatnya } \\
\text { sesamol adalah senyawa } \\
\text { sesamolin yang mana } \\
\text { ketika senyawa } \\
\text { sesamolin dipanaskan } \\
\text { akan memecah menjadi } \\
\text { oxonium ion dan sesamol } \\
\text { sehingga kadar sesamolin } \\
\text { dalam wijen berkurang } \\
\text { dan kadar sesamol } \\
\text { meningkat. }\end{array}$ \\
\hline
\end{tabular}

\section{2) Perancangan (Design)}

Selanjutnya adalah tahap perancangan design storyboard [12]. Pada tahap ini menggambarkan deskripsi setiap scene yang dideskripsikan berupa gambar. Gambar 2 adalah storyboard pada scene 1 yaitu tampilan animasi yang sekilas menjelaskan berbagai macam minyak nabati serta manfaat minyak wijen bagi kesehatan.

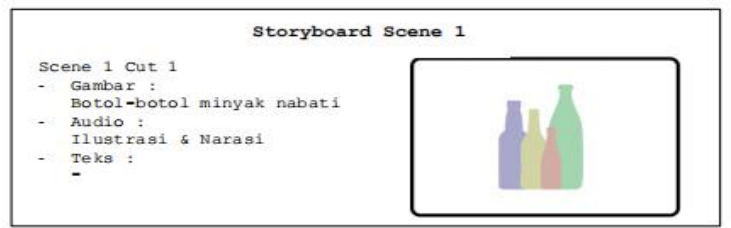

Gambar 2 Contoh Storyboard Scene 1

\section{3) Pengumpulan Materi}

Pada tahap ini pengumpulan bahan-bahan berupa file video dengan melakukan proses shooting untuk mendapatkan footage, file aset animasi yang dibutuhkan, file gambar berupa logo Politeknik Negeri Sriwijaya dan logo Teknologi Informatika Multimedia Digital, file font, file video, serta beberapa file audio berupa sound effect dan musik instrumen. Pada proses rekaman suara untuk narasi, digunakan aplikasi recording di handphone. 
Tabel III-VI merupakan beberapa contoh materi yang digunakan pada pembuatan media pembelajaran audio-visual dengan teknik motion graphic ini.

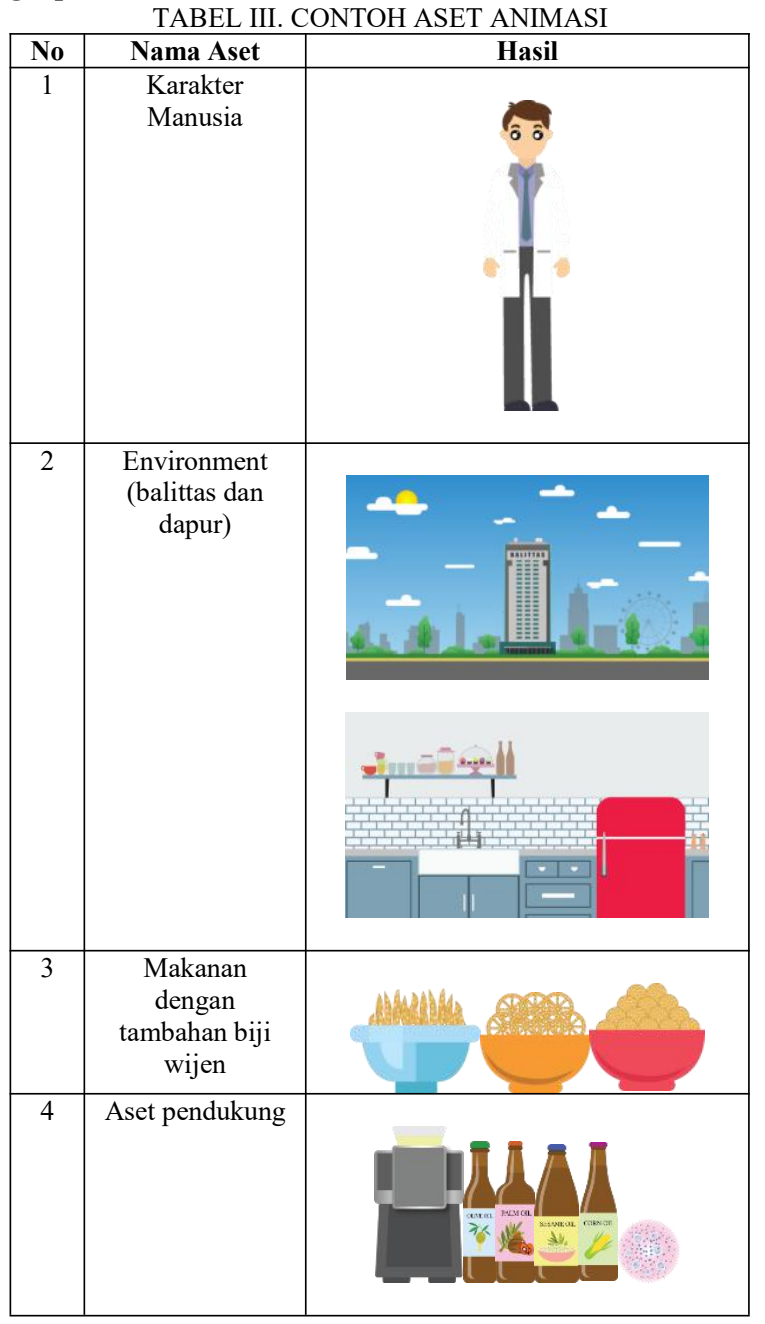

TABEL IV. CONTOH MATERI GAMBAR

\begin{tabular}{|c|c|c|c|}
\hline No & Nama file & $\begin{array}{c}\text { Format } \\
\text { file }\end{array}$ & Gambar \\
\hline 1 & Logo Polsri & png \\
\hline 2 & $\begin{array}{c}\text { Logo Teknologi } \\
\text { Informatika } \\
\text { Multimedia } \\
\text { Digital }\end{array}$ & png & \\
\hline
\end{tabular}

TABEL V. CONTOH MATERI FONT

\begin{tabular}{|c|c|c|c|c|}
\hline No & Nama & $\begin{array}{c}\text { Font } \\
\text { Style }\end{array}$ & Format & Tampilan \\
\hline 1 & Calibri & $\begin{array}{c}\text { Regular, } \\
\text { bold, } \\
\text { italic, } \\
\text { bold } \\
\text { italic }\end{array}$ & ttf & The quick brown fox \\
\hline 2 & $\begin{array}{c}\text { Century } \\
\text { Gothic }\end{array}$ & Bold & ttf & \\
The quick brown fox \\
\hline
\end{tabular}

TABEL VI. CONTOH MATERI SOUND DAN MUSIK

\begin{tabular}{|c|c|c|}
\hline No & Nama file & Format file \\
\hline 1 & Gentle & $\mathrm{mp} 3$ \\
\hline 2 & Island & $\mathrm{mp} 3$ \\
\hline 3 & Recording 4 & $\mathrm{~m} 4 \mathrm{a}$ \\
\hline
\end{tabular}

\section{4) Pembuatan}

Pada tahap pembuatan atau assembly, terdapat beberapa proses yang harus ditempuh, yaitu animating, compositing, sound \& music, editing dan rendering. Pembuatan media pembelajaran ini berdasarkan storyboard yang telah dibuat sebelumnya.

\section{a) Animating}

Proses ini adalah penggerakkan berbagai teks dan model (aset) yang telah dibuat. Terdapat beberapa tahap dan teknik yang dilakukan penulis dalam proses ini, diantaranya:

\section{- Basic Animation}

Teknik ini merupakan teknik dasar dari animasi pada After Effects. Terdapat animasi position (posisi), rotation (rotasi), scale (skala), dan opacity (transparansi). Teknik ini digunakan hampir pada setiap scene.

- Text Animation

Text Animation merupakan animasi khusus dalam teks, sehingga penulis dapat menganimasikan per huruf, per kata, ataupun per baris kalimat.

- Masking

Masking digunakan untuk menyembunyikan sebagian atau semua bagian dari sebuah objek menggunakan bentuk dari objek lain.

- Trim Paths

Teknik ini digunakan untuk menganimasikan line (garis) dengan bentuk apapun.

- In-Out Animation

Proses ini dilakukan dengan menggunakan plug-in dan dapat digunakan untuk menambahkan gerakan in - out sebuah objek.

b) Compositing

Penulis melakukan penyusunan (compositing) audio dan video animasi dari beberapa hasil renderan sebelumnya. Berikut adalah tahapannya:

- New Sequence

Tahap ini merupakan tahap awal dari compositing, yaitu membuat sequence baru. 
- Import video dan audio

Pada tahap ini penulis memilih compositioncomposition scene dan audio yang telah jadi, seperti scene1, scene2, dan seterusnya.

- Composting

Penulis menyusun potongan video dan narasi dari scene 1 sampai seterusnya di timeline sesuai dengan storyboard yang telah dibuat.

c) Sound and Music

Selanjutnya penulis melakukan editing untuk menyelaraskan antara video dan narasi yang sudah direkam sebelumnya. Berikut teknik yang digunakan dalam tahap ini:

\section{- Audio Editing}

Teknik ini merupakan teknik untuk mengatur tinggi rendahnya suara sesuai dengan satuan decibel (dB) yang diinginkan. Teknik ini digunakan pada semua audio agar tingkat kekerasan suara hampir sama rata.

- Constant Gain, Constant Power dan Exponentian Fade

Teknik ini digunakan untuk membuat audio agar bersuara pelan di awal untuk Constan Gain, dan bersuara pelan di akhir dengan menggunakan Exponetial Fade serta memperhalus transisi suara dengan menggunakan Constant Power.

\section{d) Editing}

Penulis melakukan editing untuk menyelaraskan antara video dan narasi yang sudah direkam sebelumnya.

\section{- Add Cut Point}

Teknik add cut point dilakukan pada scenescene yang masih memiliki durasi yang kurang pas, dengan cara memotong sebagian dari scene tersebut agar potongan bisa diubah kecepatannya tanpa mengubah kecepatan keseluruhan dari scene tersebut.

- Speed/Duration

Teknik ini digunakan untuk mempercepat atau memperlambat durasi dari sebuah scene. Penulis menggunakannya untuk scene yang masih memiliki durasi yang kurang pas.

\section{e) Rendering}

Tahap rendering ini dilakukan untuk menghasilkan video yang siap untuk ditonton. Disini penulis mengatur output video dengan ukuran 1920x1080 pixel, dengan format H.264 untuk menghasilkan video dengan format MP4, dan frame rate $25 \mathrm{fps}$.

\section{Perancangan Kuesioner}

Penelitian ini mengambil sampel sebanyak 7 orang responden ahli (alfa) dan 30 orang responden dari mahasiswa Teknologi Hasil Pangan Universitas Sriwijaya dengan memberikan beberapa pertanyaan mengenai teknik animasi yang dipakai, segi informasi yang disampaikan, tampilan animasi media pembelajaran yang disajikan dan kualitas audio dalam video tersebut. Respon pengujian ditunjukkan untuk memberikan kesimpulan bahwa hasil media pembelajaran audio-visual sesuai dengan tujuan pembuatan. Selain mengajukan pertanyaan, penyebaran kuesioner juga dilakukan untuk mengumpulkan biodata responden berupa nama, umur, jenis kelamin dan tingkat pendidikan. Daftar pertanyaan terdapat di Tabel VII dan VIII.

TABEL VII. PERTANYAAN KUESIONER ALFA

\begin{tabular}{|c|c|c|c|c|c|c|}
\hline \multirow[t]{2}{*}{ No } & \multirow[t]{2}{*}{ Pertanyaan } & \multicolumn{5}{|c|}{$\begin{array}{c}\text { Pilihan } \\
\text { Jawaban }\end{array}$} \\
\hline & & 1 & 2 & 3 & 4 & 5 \\
\hline 1 & $\begin{array}{l}\text { Apakah video ini menarik dari segi } \\
\text { gambar/grafis? }\end{array}$ & & & & & \\
\hline 2 & $\begin{array}{l}\text { Apakah video ini menarik dari segi } \\
\text { warna yang ditampilkan? }\end{array}$ & & & & & \\
\hline 3 & $\begin{array}{l}\text { Apakah video ini menarik dari segi } \\
\text { tipografi (teks)? }\end{array}$ & & & & & \\
\hline 4 & $\begin{array}{l}\text { Apakah video ini menarik dari segi } \\
\text { animasi/pergerakan animasi } \\
\text { (spatial)? }\end{array}$ & & & & & \\
\hline 5 & $\begin{array}{l}\text { Apakah tempo dari pergerakan } \\
\text { animasi yang terdapat dalam video } \\
\text { ini bagus? }\end{array}$ & & & & & \\
\hline 6 & $\begin{array}{l}\text { Apakah video ini menarik dari segi } \\
\text { audio/kejernihan \& kejelasan } \\
\text { suara? }\end{array}$ & & & & & \\
\hline 7 & $\begin{array}{l}\text { Apakah bagian Live Action dari } \\
\text { video ini menarik/bagus dari segi } \\
\text { kontras, depth of field dan focus? }\end{array}$ & & & & & \\
\hline 8 & $\begin{array}{l}\text { Apakah Camera Shot dari video ini } \\
\text { menarik/bagus? }\end{array}$ & & & & & \\
\hline
\end{tabular}

TABEL VIII. PERTANYAAN KUESIONER BETA

\begin{tabular}{|c|c|c|c|c|c|c|}
\hline \multirow[t]{2}{*}{ No } & \multirow[t]{2}{*}{ Pertanyaan } & \multicolumn{5}{|c|}{$\begin{array}{c}\text { Pilihan } \\
\text { Jawaban }\end{array}$} \\
\hline & & 1 & 2 & 3 & 4 & 5 \\
\hline 1 & $\begin{array}{l}\text { Apakah pembelajaran dengan } \\
\text { menggunakan motion graphics } \\
\text { seperti ini mudah Anda pahami } \\
\text { dibandingkan dengan pembelajaran } \\
\text { konvensional? }\end{array}$ & & & & & \\
\hline 2 & $\begin{array}{l}\text { Apakah pembelajaran dengan } \\
\text { menggunakan motion graphics } \\
\text { seperti ini lebih menarik dan tidak } \\
\text { membosankan? }\end{array}$ & & & & & \\
\hline 3 & $\begin{array}{l}\text { Apakah pembelajaran dengan } \\
\text { menggunakan motion graphics } \\
\text { seperti ini dapat menciptakan } \\
\text { suasana belajar yang lebih } \\
\text { menyenangkan? }\end{array}$ & & & & & \\
\hline 4 & $\begin{array}{l}\text { Menurut Anda, apakah media } \\
\text { pembelajaran seperti ini cocok } \\
\text { diterapkan dalam pembelajaran } \\
\text { sehari-hari? }\end{array}$ & & & & & \\
\hline 5 & $\begin{array}{l}\text { Apabila Anda sudah menerima } \\
\text { materi yang sama di pembelajaran } \\
\text { konvensional sebelumnya, apakah } \\
\text { dengan adanya video ini Anda } \\
\text { menjadi lebih mengerti? }\end{array}$ & & & & & \\
\hline 6 & $\begin{array}{l}\text { Apakah video ini menarik dari segi } \\
\text { gambar/grafis? }\end{array}$ & & & & & \\
\hline 7 & $\begin{array}{l}\text { Apakah video ini menarik dari segi } \\
\text { warna yang ditampilkan? }\end{array}$ & & & & & \\
\hline 8 & $\begin{array}{l}\text { Apakah video ini menarik dari segi } \\
\text { tipografi (teks)? }\end{array}$ & & & & & \\
\hline
\end{tabular}




\begin{tabular}{|l|l|l|l|l|l|l|}
\hline 9 & $\begin{array}{l}\text { Apakah video ini menarik dari segi } \\
\text { animasi/pergerakan animasi? }\end{array}$ & & & & & \\
\hline 10 & $\begin{array}{l}\text { Apakah video ini menarik dari segi } \\
\text { audio/kejernihan \& kejelasan } \\
\text { suara? }\end{array}$ & & & & \\
\hline
\end{tabular}

Keterangan: 5 : Sangat Baik, 4 : Baik, 3 : Cukup Baik, 2 : Kurang Baik, 1 : Sangat Kurang Baik.

\section{Analisis Kuesioner}

Untuk dapat menyimpulkan data yang diperoleh dari hasil kuesioner yang telah diisi, diperlukan perhitungan dengan rumus tertentu agar didapatkan persentase dari setiap jawaban responden. Dalam hal ini, penulis menggunakan persamaan sebagai acuannya. Di bawah ini merupakan skala Likert yang digunakan dalam perhitungan.

\section{E. Perhitungan Skala Likert}

Skala Likert merupakan sebuah skala untuk mengukur sikap, pendapat dan persepsi seseorang atau sekelompok orang tentang kejadian atau gejala sosial [13]. Dengan menggunakan skala Likert, variabel yang diukur dijabarkan menjadi indikator variabel yang dapat diukur. Kemudian indikator tersebut dijadikan sebagai titik tolak ukur untuk menyusun item-item instrumen yang dapat berupa pernyataan atau pertanyaan. Berikut merupakan persamaan-persamaan yang dipakai dalam skala Likert:

1) Hal pertama yang harus dilakukan adalah menentukan skor dari tiap jawaban yang diberikan. Tabel IX merupakan skor jawaban dalam penelitian ini.

TABEL IX. PENENTUAN SKOR JAWABAN

\begin{tabular}{|c|c|}
\hline Pilihan Jawaban (J) & Bobot Nilai (Bn) \\
\hline Sangat Kurang (SK) & 1 \\
\hline Kurang (K) & 2 \\
\hline Cukup (C) & 3 \\
\hline Baik (B) & 4 \\
\hline Sangat Baik (SB) & 5 \\
\hline
\end{tabular}

2) Setelah ditentukan bobot nilai setiap jawaban, tentukan skor kriteria. Untuk menghitung jumlah skor kriteria dari setiap jawaban digunakan persamaan (1).

$$
\mathrm{S}_{\mathrm{k}}=\mathrm{Bn}_{\mathrm{n}} \times \mathrm{R}
$$

Keterangan:

$\mathrm{S}_{\mathrm{k}} \quad=$ Skor Kriteria

$\mathrm{Bn}_{\mathrm{n}}=$ Bobot Nilai

$\mathrm{R} \quad=$ Jumlah Responden

Skor kriteria dari tiap jawaban ini dijadikan skala untuk menentukan di nilai berapa setiap pertanyaan dinyatakan sangat kurang, kurang, cukup, baik atau sangat baik.

3) Kemudian dihitung skor tiap jawaban dengan menggunakan persamaan (2).

$$
\mathrm{S}_{\mathrm{j}}=\mathrm{J} \times \mathrm{Bn}_{\mathrm{n}}
$$
$\mathrm{S}_{\mathrm{j}} \quad=$ Skor Jawaban
$\mathrm{J}=$ Pilihan Jawaban
$\mathrm{Bn}=$ Bobot Nilai

4) Setelah itu jumlahkan tiap skor jawaban yang ada dengan persamaan (3).

$$
\mathrm{S}_{\mathrm{t}}=\mathrm{S}_{\mathrm{sk}}+\mathrm{S}_{\mathrm{k}}+\mathrm{S}_{\mathrm{c}}+\mathrm{S}_{\mathrm{b}}+\mathrm{S}_{\mathrm{sb}}
$$

Keterangan:

$\mathrm{St}_{\mathrm{t}}=$ Skor Total

Ssk $=$ Skor Sangat Kurang

$\mathrm{S}_{\mathrm{k}} \quad=$ Skor Kurang

$\mathrm{S}_{\mathrm{c}} \quad=$ Skor Cukup

$\mathrm{Sb}_{\mathrm{b}}=$ Skor Baik

$\mathrm{S}_{\mathrm{sb}} \quad=$ Skor Sangat Baik

5) Selanjutnya untuk mengetahui persentase setiap jawaban yang dijawab oleh responden digunakan persamaan (4) menggunakan jumlah responden.

$$
P_{j}=\left(\frac{R}{R t}\right) \times 100 \%
$$

Keterangan:

$$
\begin{array}{ll}
\mathrm{P}_{\mathrm{j}} & =\text { Persentase Jawaban } \\
\mathrm{R} & =\text { Jumlah Responden } \\
\mathrm{R}_{\mathrm{t}} & =\text { Jumlah Responden Total } \\
100 \% & =\text { Bilangan Tetap }
\end{array}
$$

6) Untuk mengetahui persentase total jawaban dari para responden dengan menggunakan persamaan (5).

$$
\mathrm{P}_{\mathrm{t}}=\left(\frac{\mathrm{St}}{\mathrm{Skt}}\right) \times 100 \%
$$

Keterangan:

$$
\begin{array}{ll}
\mathrm{Pt}_{\mathrm{t}} & =\text { Persentase Total } \\
\mathrm{St}_{\mathrm{t}} & =\text { Skor Total } \\
\mathrm{Skt}_{\mathrm{kt}} & =\text { Skor Kriteria Tertinggi } \\
100 \% & =\text { Bilangan tetap }
\end{array}
$$

7) Jika masing-masing pertanyaan sudah diketahui skornya maka langkah terakhir adalah mencari rerata skor dari pengujian dengan persamaan (6).

$$
\text { Rerata }=\frac{\mathrm{St} 1+\mathrm{St} 2+\mathrm{St} 3+\mathrm{St} 4+\ldots}{\text { Jumlah Pertanyaan }}
$$

Keterangan:

St1 = Skor Total Pertanyaan 1

St2 $=$ Skor Total Pertanyaan 2

$\mathrm{S}_{\mathrm{t} 3}=$ Skor Total Pertanyaan 3

$\mathrm{S}_{\mathrm{t} 4}=$ Skor Total Pertanyaan 4

\section{HASIL DAN PEMBAHASAN}

\section{A. Hasil}

Setelah melakukan serangkaian tahap dalam pembuatan media pembelajaran audio-visual ini, menghasilkan video yang berdurasi 7 menit 58 detik dengan format video *.mp4. Video ini dapat diputar hampir pada semua perangkat lunak pemutar video ternama saat ini. Peneliti mencoba untuk memutarnya pada Windows Media Player. Gambar 3 dan 4 merupakan beberapa tampilan dari video media pembelajaran audio-visual.

Keterangan: 


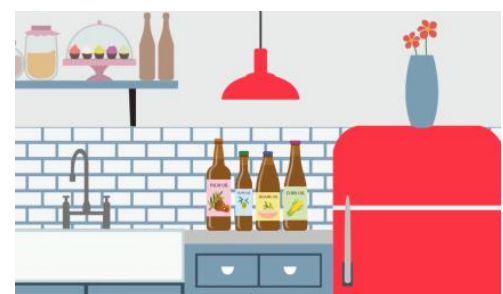

Gambar 3 Tampilan Awal video
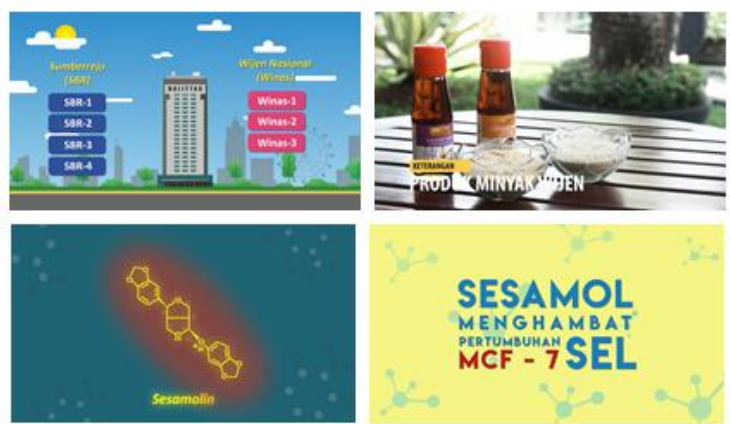

SESAMOL

MENGHAMBAT MCF - 7 SEL

Gambar 4 Tampilan yang Menjelaskan Inti Materi

\section{B. Pengujian}

\section{1) Deskripsi Pengujian}

Setelah melakukan serangkaian tahap dalam pembuatan video media pebelajaran ini, peneliti selanjutnya melakukan pengujian (testing). Pengujian dibagi menjadi dua, yaitu pengujian Alfa dan pengujian Beta dari hasil video media pembelajaran kepada beberapa responden dengan menyebarkan kuesioner secara online.

\section{2) Pengujian Alfa}

Pengujian alfa dilakukan untuk meninjau apakah animasi yang telah dibuat berjalan dengan baik. Dalam pengujian dilakukan oleh para ahli animasi dengan melihat hasil akhir video yang telah di-render sebelumnya, sehingga dapat dinilai dari segi penampilan animasi. Adapun tahapan-tahapan pengujian alfa sebagai berikut:

a. Memberikan link kuisioner online kepada responden alfa.

b. Responden alfa membuka link kuisioner dan menonton video media pembelajaran yang telah disediakan.

c. Responden alfa memberikan penilaian atau mengisi kuesioner.

3) Pengujian Beta

Pengujian beta dilakukan bertujuan untuk meninjau apakah animasi yang telah dibuat dapat memberikan pemahaman informasi kepada mahasiswa tentang sesamol sebagai zat untuk menghambat pertumbuhan kanker payudara. Pengujian ini dilakukan oleh mahasiswa Jurusan Teknologi Hasil Pertanian Universitas Sriwijaya secara online. Adapun tahapan-tahapan pengujian yang dilakukan oleh responden sebagai berikut:

a. Memberikan link kuisioner online kepada responden beta.

b. Responden beta membuka link kuesioner dan menonton video media pembelajaran yang telah disediakan.

c. Responden beta memberikan penilaian atau mengisi kuesioner.

\section{Data Hasil Pengujian}

\section{1) Data Hasil Pengujian Alfa}

Pengujian alfa dilakukan untuk mengetahui kelayakan media pembelajaran audio-visual yang dibuat. Penilaian kelayakan video dilakukan oleh ahli di bidang animasi khususnya dan multimedia pada umumnya, dengan melihat dari jurusan pendidikan dan pekerjaannya di bidang animasi ataupun multimedia. Para ahli bukan hanya berasal dari Kota Palembang, namun berada di luar Kota Palembang seperti Makassar, Jogja, dan Bandung.

\begin{tabular}{|c|c|c|c|c|c|c|}
\hline \multirow[t]{2}{*}{ No } & \multirow[t]{2}{*}{ Pertanyaan } & \multicolumn{5}{|c|}{$\begin{array}{c}\text { Pilihan } \\
\text { Jawaban }\end{array}$} \\
\hline & & 1 & 2 & 3 & 4 & 5 \\
\hline 1 & $\begin{array}{l}\text { Apakah video ini menarik dari } \\
\text { segi gambar/grafis? }\end{array}$ & & & 3 & 3 & 1 \\
\hline 2 & $\begin{array}{l}\text { Apakah video ini menarik dari } \\
\text { segi warna yang ditampilkan? }\end{array}$ & & 1 & 2 & 2 & 2 \\
\hline 3 & $\begin{array}{l}\text { Apakah video ini menarik dari } \\
\text { segi tipografi (teks)? }\end{array}$ & & 1 & 3 & 2 & 1 \\
\hline 4 & $\begin{array}{l}\text { Apakah video ini menarik dari } \\
\text { segi animasi/pergerakan } \\
\text { animasi (spatial)? }\end{array}$ & & 1 & 3 & 2 & 1 \\
\hline 5 & $\begin{array}{l}\text { Apakah tempo dari pergerakan } \\
\text { animasi yang terdapat dalam } \\
\text { video ini bagus? }\end{array}$ & & 2 & 2 & 2 & 1 \\
\hline 6 & $\begin{array}{l}\text { Apakah video ini menarik dari } \\
\text { segi audio/kejernihan } \& \\
\text { kejelasan suara? }\end{array}$ & & 3 & 2 & 1 & 1 \\
\hline 7 & $\begin{array}{l}\text { Apakah bagian Live Action } \\
\text { dari video ini menarik/bagus } \\
\text { dari segi kontras, depth of field } \\
\text { dan focus? }\end{array}$ & & 2 & 1 & 3 & 1 \\
\hline 8 & $\begin{array}{l}\text { Apakah Camera Shot dari } \\
\text { video ini menarik/bagus? }\end{array}$ & & 2 & 1 & 3 & 1 \\
\hline
\end{tabular}

Keterangan : 5 : Sangat Baik, 4 : Baik, 3 : Cukup Baik, 2 Kurang Baik, 1 : Sangat Kurang Baik

\section{2) Data Hasil Pengujian Beta}

Data pengujian beta ialah para responden yang terdiri dari 30 mahasiswa Jurusan Teknologi Hasil Pertanian Universitas Sriwijaya. Dengan tujuan video dapat memberikan informasi dengan jelas tentang materi yang disampaikan. 
TABEL XI. HASIL PENGUJIAN BETA

\begin{tabular}{|c|c|c|c|c|c|c|}
\hline \multirow[t]{2}{*}{ No } & \multirow[t]{2}{*}{ Pertanyaan } & \multicolumn{5}{|c|}{ Pilihan Jawaban } \\
\hline & & 1 & 2 & 3 & 4 & 5 \\
\hline 1 & $\begin{array}{l}\text { Apakah pembelajaran } \\
\text { dengan menggunakan } \\
\text { motion graphics } \\
\text { seperti ini mudah Anda } \\
\text { pahami dibandingkan } \\
\text { dengan pembelajaran } \\
\text { konvensional? }\end{array}$ & & 1 & 2 & 17 & 10 \\
\hline 2 & $\begin{array}{l}\text { Apakah pembelajaran } \\
\text { dengan menggunakan } \\
\text { motion graphics } \\
\text { seperti ini lebih } \\
\text { menarik dan tidak } \\
\text { membosankan? }\end{array}$ & & & 2 & 10 & 18 \\
\hline 3 & $\begin{array}{l}\text { Apakah pembelajaran } \\
\text { dengan menggunakan } \\
\text { motion graphics } \\
\text { seperti ini dapat } \\
\text { menciptakan suasana } \\
\text { belajar yang lebih } \\
\text { menyenangkan? }\end{array}$ & & 1 & 5 & 11 & 13 \\
\hline 4 & $\begin{array}{l}\text { Menurut Anda, apakah } \\
\text { media pembelajaran } \\
\text { seperti ini cocok } \\
\text { diterapkan dalam } \\
\text { pembelajaran sehari- } \\
\text { hari? }\end{array}$ & & 2 & 6 & 14 & 8 \\
\hline 5 & $\begin{array}{l}\text { Apabila Anda sudah } \\
\text { menerima materi yang } \\
\text { sama di pembelajaran } \\
\text { konvensional } \\
\text { sebelumnya, apakah } \\
\text { dengan adanya video } \\
\text { ini Anda menjadi lebih } \\
\text { mengerti? }\end{array}$ & & 1 & 4 & 16 & 9 \\
\hline 6 & $\begin{array}{l}\text { Apakah video Motion } \\
\text { Graphics ini menarik } \\
\text { dari segi gambar / } \\
\text { grafis? }\end{array}$ & & 1 & 4 & 13 & 12 \\
\hline 7 & $\begin{array}{l}\text { Apakah video Motion } \\
\text { Graphics ini menarik } \\
\text { dari segi warna yang } \\
\text { ditampilkan? }\end{array}$ & & & 4 & 14 & 12 \\
\hline 8 & $\begin{array}{l}\text { Apakah video Motion } \\
\text { Graphics ini menarik } \\
\text { dari segi tipografi } \\
\text { (teks)? }\end{array}$ & & 2 & 8 & 14 & 6 \\
\hline 9 & $\begin{array}{l}\text { Apakah video Motion } \\
\text { Graphics ini menarik } \\
\text { dari segi animasi / } \\
\text { pergerakan animasi? }\end{array}$ & & & 7 & 11 & 12 \\
\hline 10 & $\begin{array}{l}\text { Apakah video Motion } \\
\text { Graphics ini menarik } \\
\text { dari segi audio / } \\
\text { kejernihan dan } \\
\text { kejelasan suara? }\end{array}$ & & 6 & 7 & 8 & 9 \\
\hline
\end{tabular}

\section{Analisis}

\section{1) Analisis Data Pengujian Alfa}

Analisis data dalam pengujian alfa, dihitung berdasarkan masing-masing poin dari setiap pertanyaan dengan menggunakan skala Likert. Responden alfa ini sebanyak 7 orang. Adapun skor dan persentase keberhasilannya pada Tabel 12 dan grafik persentase pada Gambar 5.
TABEL XII. SKOR KRITERIA ALFA

\begin{tabular}{|c|c|}
\hline Keterangan & Range Nilai \\
\hline Sangat Baik & $29-35$ \\
\hline Baik & $22-28$ \\
\hline Cukup & $15-21$ \\
\hline Kurang Baik & $8-14$ \\
\hline Sangat Kurang Baik & $0-7$ \\
\hline
\end{tabular}

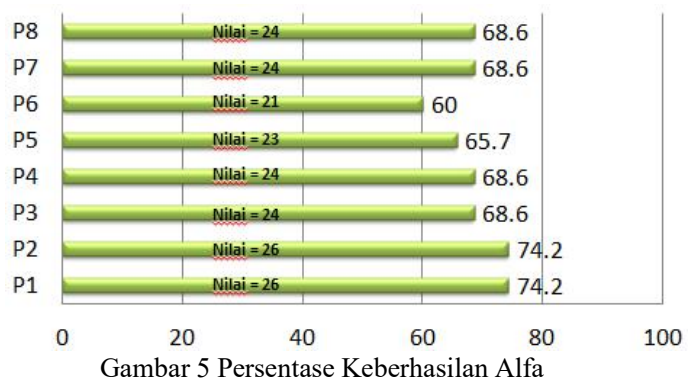

\section{2) Analisis Data Pengujian Beta}

Sama seperti pengujian alfa, dalam pengujian beta juga dihitung berdasarkan masing-masing point dari setiap pertanyaan dengan menggunakan skala Likert. Responden beta ini sebanyak 30 orang. Adapun skor dan persentase keberhasilannya seperti pada Tabel XIII dan Gambar 6.

TABEL XIII. SKOR KRITERIA BETA

\begin{tabular}{|c|c|}
\hline Keterangan & Range Nilai \\
\hline Sangat Baik & $121-150$ \\
\hline Baik & $91-120$ \\
\hline Cukup & $61-90$ \\
\hline Kurang Baik & $31-60$ \\
\hline Sangat Kurang Baik & $0-30$ \\
\hline
\end{tabular}

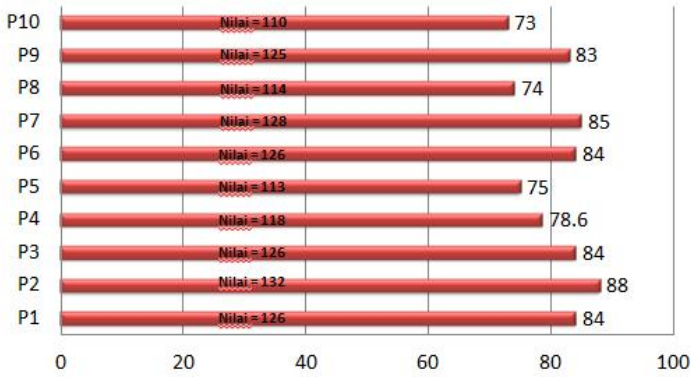

Gambar 6 Persentase Keberhasilan Beta

\section{KESIMPULAN}

Berdasarkan perancangan dan realisasi media pembelajaran audio-visual tentang peningkatan sesamol sebagai zat penghambat pertumbuhan sel kanker dengan menggunakan teknik motion graphic yang telah dikerjakan, maka dapat diambil beberapa kesimpulan yaitu media pembelajaran audio-visual dengan menggunakan teknik motion graphic ini menarik sehingga informasi yang ingin disampaikan mudah untuk dicerna audien. 
Berdasarkan hasil video, data kuesioner pada pengujian alfa dan beta, berikut hasil yang diperoleht:

1) Media pembelajaran audio-visual tentang peningkatan sesamol sebagai zat penghambat pertumbuhan sel kanker dengan menggunakan teknik motion graphic ini berdurasi 7 menit 58 detik dan dibuat dengan beberapa teknik seperti tracing, clipping mask, basic animation, text animation, masking, trim paths, in-out animation, add cut point dan speed duration.

2) Hasil pengujian alfa menyatakan bahwa media pembelajaran audio-visual ini mempunyai nilai akhir sebesar 24 berada di kategori "baik" dan mempunyai persentase keberhasilan mencapai $\mathbf{6 8 , 6 \%}$. Maka media pembelajaran audio-visual ini layak secara penampilan untuk dipublikasian kepada audien.

3) Hasil pengujian beta menyatakan bahwa media pembelajaran audio-visual ini mempunyai nilai akhir sebesar 121,8 berada di kategori "sangat baik" dan mempunyai persentase keberhasilan mencapai 81,2\%. Maka media pembelajaran audio-visual ini layak dijadikan media untuk membantu para pelaku pendidikan dalam mengajar dengan materi terkait.

\section{SARAN}

Penulis menyadari masih banyak kekurangan dalam proses perancangan media pembelajaran audio-visual yang penulis buat. Untuk itu penulis memberikan beberapa saran diantaranya:

1) Diharapkan agar dimasa yang akan datang, media pembelajaran audio-visual ini dapat digunakan pelaku pendidikan dalam membantu proses belajar mengajar.

2) Sebaiknya dalam pembuatan media pembelajaran audio-visual ini dapat ditambahkan lebih banyak lagi motion graphic karena masih ada beberapa bagian video yang belum dimaksimalkan.

\section{REFERENS}

[1] A. D. Pangawikan, U. Santoso, Suparmo, dan P. Hastuti, "Enhancing Antioxidant Activity of Indonesian Sesame Oil (Sesamum indicum) by Heat Treatment," hal. 1, 2016.

[2] M. Mahelda, N. Hartini, "Post-traumatic Growth pada Pasien Kanker Payudara Pasca Mastektomi Usia Dewasa Madya," Jurnal Psikologi Klinis dan Kesehatan Mental, vol. 1, no. 2, hal. 68, 2012.

[3] M. Husni, S. Romadoni, dan D. Rukiyati, "Hubungan Dukungan Keluarga dengan Kualitas Hidup Pasien Kanker Payudara di Instalasi Rawat Inap Bedah RSUP Dr, Mohammad Hoesin Palembang Tahun 2012," Jurnal Keperawatan Sriwijaya, vol. 2, no. 2, hal. 78, 2015.

[4] A. Jacklin, C. Ratledge, K. Welham, D. Bilko, dan C. J. Newton, "The Sesame Seed Oil Constituent, Sesamol, Induces Growth Arrest and Apoptosis of Cancer and Cardiovascular Cells," New York Academy of Science, hal. 377, 2013.

[5] N. Suryani, "Utilization of Digital Media to Improve The Quality and Attractiveness of The Teaching of History," Proceeding The 2nd International Conference On Teacher Training and Education Sebelas Maret University, vol. 2, no $1,2016$.

[6] F. K. Astuti, E. Cahyono, Supartono, N. C. Van, N. T. Duong, "Effectiveness of Elements Periodic Table Interactive Multimedia in Nguyen Tat Thanh High School," International Hournal of Indonesian Education and Teaching, vol. 2, no. 1, 2018.

[7] S. Haryoko, "Efektivitas Pemanfaatan Media Audio-Visual sebagai Alternatif Optimalisasi Model Pembelajaran," JurnalEdukasi@Elektro, vol. 5, no. 1, hal. 4-9, 2009.

[8] R. Tamami, "Pemanfaatan Media Pembelajaran Interaktif MPI) Powerpoint untuk Visualisasi Konsep Menggambar Grafik Persamaan Garis Lurus," Indonesian Digital Journal of Mathematics and Education, vol. 1, 2014.

[9] W. Wiana, M. S. Barliana, A. A. Riyanto, "The Effectiveness of Using Interactive Multimedia Based onMotion Graphic in Concept Mastering Enhancement and Fashion Designing Skill in Digital Format," International Journal of Emerging Technologies in Learning, vol. 3, no. 2 2018.

[10] R. Suryani, H. Saputra, A. Sutrisman, "Implementasi Animasi 2d pada Iklan Layanan Masyarakat sebagai Sosialisasi Penyakit DBD," Jurnal Rekam, vol. 5, no. 2, 2019.

[11] A. R. Rovianto, Pengembangan Iklan Layanan Masyarakat dengan Pendekatan Infografis tentang Pentingnya Konsumsi Air Putih. 2015.

[12] S. Mahardika, dan C. A. Fathoni, "Storyboard dalam Pembuatan Motion Graphic," 2013.

[13] S. Yusi, dan U. Idris, Metodologi Penelitian : untuk Ekonomi, Bisnis dan Sosial, Universitas Sriwijaya, 2016. 